\title{
La teoría literaria marxista en Francia: una revisión de las propuestas de Lucien Goldmann y Pierre Macherey
}

\author{
Violeta GARRIDO \\ Universitat de Barcelona \\ violetagasan@gmail.com \\ ORCID: 0000-0002-8678-8390
}

\section{Resumen}

Este artículo se propone hacer un recorrido exhaustivo por los aportes realizados por dos de los teóricos marxistas franceses más recientes y a la vez menos divulgados en el ámbito académico hispano, Lucien Goldmann y Pierre Macherey. Al confrontar sus ideas originales con las tesis principales de las estéticas marxistas más clásicas y consolidadas (la adorniana y la luckásiana), se observa la considerable influencia que estas ejercieron en otras escuelas y, paralelamente, lo condicionadas que estaban por el estructuralismo y el posestructuralismo.

Palabras clave: Lukács. Adorno. Althusser. Ideología. Producción literaria. Estructuralismo.

\section{Résumé}

Cette article se propose de faire un parcours exhaustif par les contributions qui on fait deux des théoriques marxistes français les plus récents et à la fois les moins divulgués dans le domaine académique hispanique, Lucien Goldmann et Pierre Macherey. En confrontant leurs idées originales avec les thèses principales des esthétiques marxistes les plus classiques et consolidées (la adornienne et la luckásienne), on observe qu'ils on exercé une influence considérable dans autres écoles et, parallèlement, qu'ils on été conditionnés par le structuralisme et le post-estructuralisme.

Mots clé : Lukács. Adorno. Althusser. Idéologie. Production littéraire. Structuralisme.

\begin{abstract}
This paper makes a comprehensive explanation of Lucien Goldmann and Pierre Macherey's contributions to the marxist literary theory, whose thought has circulated very poorly on the hispanic academic field. By confronting their original ideas with the principal thesis of the most classical and consolidated marxist aesthetics (the adornian and the luckasian), we observe the significant influence that they exercised in others schools of thought
\end{abstract}

* Artículo recibido el 11/11/2019, aceptado el 7/01/2020. 
and, at the same time, how conditioned they were by the structuralism and poststructuralism.

Keywords: Lukacs. Adorno. Althusser. Ideology. Literary production. Structuralism.

\section{Introducción}

La teoría literaria de corte marxista en Francia, un campo al que por lo general se le ha prestado poca atención a nivel académico en los países de habla hispana, presenta un desarrollo fulgurante a partir de la segunda mitad del siglo XX. No hay duda que, a tenor de las políticas culturales que se estaban implementando en la Unión Soviética, el debate mantenido entre György Lukács y Theodor Adorno, Walter Benjamin y Bertolt Brecht, entre otros, a propósito del valor de la narrativa modernista en contraposición al realismo fue determinante para su desarrollo; prueba de ello es la famosa "Querelle du Réalisme» de los años 30 en la que Fernand Léger y, sobre todo, Louis Aragon expusieron la caracterización de la literatura como totalidad, como expresión consciente de la realidad social y parte integrante del combate por modificar esa realidad (Aragon, 1987: 96), la obligación de preservar democráticamente el patrimonio cultural para las generaciones venideras y, por último, la necesidad de fundar un "nouveau réalisme» que, reconociéndose sin dogmatismos en la tradición de todas aquellas corrientes artísticas previas que hicieron de la realidad su "grande affaire» (una cuestión de actitud ante los hechos más que de forma), efectuase un "retour à la réalité» tras los experimentos surrealistas y dadaístas, del cual a su juicio también forma parte el trabajo de escritores como Kafka o Maiakovski. Sin embargo, a partir de los ańos 60 tiene lugar un despliegue teórico muy original influido por el estructuralismo, la narratología y otras corrientes de pensamiento contemporáneas que pretende explicar la manera sutil en la que opera una instancia como la ideología en el texto literario. El propósito de este artículo es presentar e interrelacionar los aportes teóricos de Lucien Goldmann y Pierre Macherey, dos coetáneos cuyos trabajos fueron fundamentales para desprenderse del encorsetado esquema normativo heredado de Lukács, incorporar un nuevo vocabulario conceptual e incluir ámbitos de estudio como el de la recepción.

El primer bloque de este artículo está dedicado a las investigaciones llevadas a cabo por Lucien Goldmann. En él rastreamos la presencia de la totalidad lukácsiana en el sofisticado concepto goldmanniano de visión del mundo, que refiere un tipo de conciencia colectiva coherente y estructurada presente en algunas obras literarias y que, por medio de la ficción, formula los valores y esclarece la acción de ciertos grupos sociales. El influjo de Lukács en Goldmann, de cuya obra era perfectamente conocedor, se hace patente además en el estricto criterio normativo que maneja este último: solamente gozan de visión del mundo y forman parte de la verdadera literatu- 
ra (la única que es susceptible de estudiarse) las obras que exhiben una coherencia fuertemente significativa. Después de hacer notar que para Goldmann la noción lukácsiana de reificación es central en su consideración de que la estructura del género novelesco y la del intercambio económico se vuelven análogas, repasamos la convergencia con Adorno en lo concerniente a la pertinencia y a la fidelidad histórica de la narrativa modernista, de la que Goldmann es un acérrimo defensor por cuanto considera que retrata con exactitud la deshumanización de la vida social en el capitalismo tardío. Todo ello le lleva a teorizar que los escritores modernistas intentan deshacerse del yugo del valor de cambio por medio de una escritura vanguardista «de la ausencia» que no encarna ningún tipo de valor productivo o propositivo y que, debido a este nihilismo, carece de la coherencia suficiente para articular una visión del mundo.

En el segundo bloque abordamos la trayectoria de Pierre Macherey, quien reflexiona sobre la singular presencia de la ideología en las obras literarias e intenta integrar las perspectivas brechtianas y benjaminianas sobre la literatura como producción -sin olvidar las aproximaciones narratológicas y estructuralistas propias de la época- a una teoría pretendidamente holista de la literatura que quiere ser, a la vez, marcadamente materialista. Lo primero que destacamos son las distintas críticas que dirige hacia Garaudy, Sartre y Goldmann, que no han sabido incorporar eficazmente a sus hipótesis la idea de que la literatura se caracteriza por ser el resultado de un proceso de producción en constante circulación, puesto que, entre otras cosas, sus tesis han contribuido a sacralizar la figura del autor y de su creación. El hecho de que las obras, en lugar de ser concebidas una vez y para siempre, se reproduzcan continuamente como discursos modificados y sean objeto de pactos subjetivos entre los autores y los lectores explicaría por qué la literatura es capaz de pervivir y de seguir conmoviendo más allá de su contexto histórico de surgimiento. Por otro lado, Macherey, de formación althusseriana, sostiene que las obras literarias son formas ideológicas a través de las cuales se demuestran, muchas veces inconscientemente y sin el conocimiento expreso del autor, y gracias sobre todo a las operaciones efectuadas sobre la forma, las incongruencias y las inconsistencias del sistema de representaciones sociales que llamamos ideología.

\section{Estructuralismo genético y dialéctica forma-contenido en Lucien Goldmann}

\subsection{El análisis estructural de la creación literaria}

En una época atravesada de punta a punta por los estructuralismos ${ }^{1}$, Lucien Goldmann se distancia metodológicamente de las afirmaciones meramente postulati-

\footnotetext{
${ }^{1}$ El mismo Goldmann (1964: 338) definía su método como un estructuralismo porque parte de la hipótesis de que «tout comportement humain est un essai de donner une réponse significative à une situation particulière» y porque «les réalités humaines se présentent-elles comme des processus à double face: destructuration des structurations anciennes et structuration de totalités nouvelles aptes à créer des
} 
vistas de Lukács, Adorno y otros -aunque se apoye en ellos en otros aspectos, como se verá más adelante- al poner en marcha un aparato argumentativo de finalidad probatoria (Sasso, 1979: 7) que, en lugar de perseguir el establecimiento de relaciones entre los contenidos presentes en las obras literarias y aquellos albergados en la conciencia colectiva (como pretendían en aquel tiempo la mayoría de escuelas de sociología literaria $^{2}$ ), se consagra más bien a la comprensión honda tanto de las estructuras significativas que conforman la conciencia de los grupos sociales existentes como de la expresión práctica de dicha conciencia. De este modo, la obra literaria sería el producto cultural que alcanza en el plano imaginario «une cohérence jamais ou rarement atteinte dans la réalité» (Goldmann, 1977: 29) ${ }^{3}$. El matiz, aunque pueda no parecerlo a primera vista, es muy relevante: la obra literaria es uno de los elementos constitutivos de la conciencia colectiva, y en absoluto su simple reflejo, puesto que faculta que los miembros del grupo social sobre el que opera la obra en cuestión, cuya conciencia individual es por lo demás caótica y está poblada de tendencias diversas y contradictorias, se aproximen a desentrañar la significación objetiva -que hasta entonces permanecía más o menos inconsciente u oculta para el individuo- de su pensamiento, su afectividad y su comportamiento (Goldmann, 1977: 23-24).

Este carácter avanzado de la obra literaria respecto a la conciencia individual viene dado por el hecho de que en ella se expresa lo que Goldmann llama una «vision du monde» coherente y significativa. Podría definirse como un tipo de conciencia colectiva que aprehende la totalidad de las relaciones humanas y de las relaciones entre los seres humanos y el conjunto del universo (Goldmann, 1977: 23) ${ }^{4}$. Aunque la

équilibres qui sauraient satisfaire aux nouvelles exigences des groupes qui les élaborent». Incluso considera que ciertos pensadores anteriores a la emergencia de dicha corriente de pensamiento, como Freud, Hegel, Marx, Piaget, Gramsci o Lukács son representantes ya sea de uno u otro plano del estructuralismo genético (Goldmann, 1966: 123).

${ }^{2}$ Goldmann somete a crítica las corrientes de la sociología de la literatura que alientan dicho procedimiento -como las encabezadas por Robert Escarpit, Alphons Silbermann o Edoardo Sanguineti, entre otros- porque la recuperación por parte del escritor de elementos de contenido de la conciencia colectiva o simplemente del aspecto empírico de la sociedad que lo envuelve no es casi nunca ni sistemática ni general y se encuentra solamente en ciertos puntos de la obra; sostener lo contrario soslaya deja escapar la unidad misma de la obra, es decir, su carácter específicamente literario (Goldmann, 1964: 344-345).

${ }^{3}$ En este sentido, la función que cumple la creación literaria y artística en general es, a nivel colectivo, análoga a la que posee el mecanismo de sublimación para el psicoanálisis en el plano individual: «apporter sur le plan imaginaire cette cohérence dont les hommes sont frustrés dans la vie réelle, exactement comme, sur le plan individuel, les rêves, les délires et l'imaginaire procurent l'objet ou le substitut de l'objet que l'individu n'avait pas pu posséder réellement» (Goldmann, 1970: 114).

${ }^{4}$ La conciencia colectiva entendida por Goldmann como una entidad orgánica formada por un gran número de individuos con su psiquismo, sus conductas, sus aspiraciones, etc. y por el conjunto de 
teoría del reflejo no tiene cabida en el corpus teórico goldmanniano, la huella lukácsiana es, en el sentido al que hemos aludido hace un momento, más que evidente: en Goldmann la totalidad sigue revistiendo esa percepción histórica y dinámica de las relaciones sociales que se encontraba originalmente en Lukács, con la salvedad de que para el primero lo que la totalidad expresada en una determinada visión del mundo acaba mostrando es la "conscience possible» del grupo social al que la obra literaria se dirige o se refiere (Fabre, 2001: 21); es decir, las potencialidades de actuación transformadora con las que cuenta, sin saberlo, dicho grupo. Así, la coherencia respecto al mundo que una obra logra en el plano de la ficción (y que, como ya se ha señalado, los miembros del grupo solo experimentan en su cotidianidad de manera lejana y aproximada) no es de orden lógico o factual -afirmación que desafía claramente el principio mimético tradicional-, sino en buena medida utópica o proyectiva. Las nociones de "visión del mundo», "coherencia», "conciencia posible» o «estructura significativa», tal y como las entiende Goldmann, llevan implícita la idea de que la literatura encarna, representa o explora la posibilidad, y muy a menudo la presencia efectiva, de un ideal de ser humano (Goldmann, 1977: 23).

Cabría puntualizar que el estructuralismo genético -método «monista» por cuanto se niega a aceptar una separación radical «entre les lois fondamentales qui régissent le comportement créateur dans le domaine de la culture et celles qui régissent le comportement quotidien de tous les hommes dans la vie sociale et économique» (Goldmann, 1977: 20)- presupone la incapacidad del individuo para elaborar por sí mismo una «vision du monde». Como figura o imagen, si se quiere, filosófica universal de la sociedad, la visión del mundo es confeccionada por una colectividad que Goldmann prefiere llamar «sujet transindividuel»- compuesta por «groupes sociaux privilégiés»" , pero es la «individualité exceptionnelle» del escritor (Goldmann,

reglas que son objeto de un consenso más o menos fuerte en la sociedad es, por cierto, una idea que se hace eco de la postura durkheimiana de forma muy manifiesta: «L'ensemble des croyances et des sentiments communs à la moyenne des membres d'une même société forme un système déterminé qui a sa vie propre; on peut l'appeler la conscience collective ou commune [...]; elle [la conciencia colectiva] est indépendante des conditions particulières où les individus se trouvent placés; ils passent et elle reste [...]. Elle est le type psychique de la société» (Durkheim, 1967: 48).

5 Para Goldmann, el «privilegio» de un grupo social no lo es en un sentido material o jurídico. Basándose tácitamente en la concepción lukácsiana, ya tradicional, de la ideología como falsa conciencia, Goldmann (Goldmann, 1977: 23) establece una distinción sociológica entre la ideología (o conciencia ideológica) y la visión del mundo. La conciencia ideológica de los grupos no privilegiados (familiares, profesionales, etc.) los conmina a dirigirse colectivamente hacia la mejora de ciertas posiciones en el interior de una estructura social dada. Por otro lado, los grupos privilegiados (que pueden identificarse con la clase) poseen una visión del mundo porque se orientan hacia una reorganización global de las relaciones humanas, o bien hacia una conservación global de la estructura social existente, por lo que las preocupaciones de unidad y coherencia se vuelven muy importantes. Dada la complejidad de la 
1977: 23) la que finalmente la transforma en obra de arte capaz de recoger estéticamente las aspiraciones y las tendencias no necesariamente declaradas de la conciencia colectiva. Sin negar el sentido eminentemente social de la creación literaria, Goldmann (1963: 345) hace énfasis a su vez en que se trata de un producto que manifiesta la idiosincrasia altamente individual del escritor:

le caractère collectif de la création littéraire provient du fait que les structures de l'univers de l'œuvre sont homologues aux structures mentales de certains groupes sociaux ou en relation intelligible avec elles, alors que sur le plan des contenus, c'est-àdire de la création d'univers imaginaires régis par ces structures, l'écrivain a une liberté totale.

Es en Le Dieu caché (1959) donde Goldmann asegura poder verificar estas hipótesis, en parte inspirado por las consideraciones sobre la tragedia que hizo Lukács en El alma y las formas (1911). En este estudio "matérialiste et dialectique» (Goldmann, 1959: 14) sobre la visión trágica proyectada en las tragedias de Racine y en las Pensées (1669) de Pascal, la premisa principal -resumida y emancipada aquí de las minuciosas observaciones historiográficas que son laterales al tema propiamente literario- es la siguiente: la «noblesse de robe» de la Francia del siglo XVII, excluida progresivamente del poder por la monarquía de Luis XIV y suplantada en sus funciones por la nueva «bureaucratie des commissaires» centralizada, encuentra en la corriente del jansenismo más radical de Port-Royal la cristalización ideológica de su situación social; una cristalización que acaba desembocando en una «vision du monde» trágica que propugna el aislamiento y la no participación en la vida pública. El postulado jansenista de la existencia paradójica de un Dios siempre presente y siempre ausente, mudo y riguroso, se halla latente en las obras de Pascal y de Racine, cuyas personalidades creativas consiguieron, con la expresión de la angustia trágica, depositar también en sus creaciones la «conscience possible» de su clase, que para Goldmann impli$\mathrm{ca}$

la compréhension rigoureuse et précise du monde nouveau créé par l'individualisme rationaliste, avec tout ce qu'il contenait de positif, de précieux et surtout de définitivement acquis pour la pensée et la conscience humaines, mais en même temps par le refus radical d'accepter ce monde comme seule chance et seule perspective de l'homme (Goldmann, 1959: 43).

cuestión, solo puede existir un número limitado de visiones del mundo, que para Goldmann son el racionalismo, el empirismo, la visión trágica y el pensamiento dialéctico (Fabre, 2001: 21). 


\subsection{La problematización del fundamento socio-económico de la novela}

Entender, como hace Goldmann en Pour une sociologie du roman (1964), que la novela es una «recherche dégradée de valeurs authentiques dans un monde inauthentique» (Goldmann, 1964: 30) comporta al menos dos cosas. La primera, el enorme peso que adquieren en la propuesta teórica de Goldmann las tesis lukácsianas de Die Theorie des Romans, y también, en menor medida, algunas de las de René Girard en Mensonge romantique et vérité romanesque (1961). Con Girard, quien a juicio de Goldmann ofrece una precisión importante al análisis lukcásiano desde una retórica heideggeriana, coincide nuestro autor en que la degradación del mundo novelesco se manifiesta a través de una mediación más o menos grande que acorta progresivamente la distancia entre el deseo metafísico del héroe y su búsqueda auténtica (Goldmann, 1964: 29-31). Ejemplos de este «mediador del deseo» (que puede ser interno o externo) serían Amadís de Gaula para Don Quijote, las heroínas de las novelas románticas para Emma Bovary o Mme. de Rênal para Julien Sorel, entre otros (Girard, 1985).

La segunda, como consecuencia de la anterior, es que el problema que debe abordar entonces de forma primordial la sociología de la novela es el de la relación existente entre la forma novelesca en sí y la estructura del medio social en el interior del cual aquella se ha desarrollado. Al suscribir el análisis marxista de la reificación, según el cual la sustitución del valor de uso por el valor de cambio provoca una suerte de perversión en las relaciones de conciencia de los seres humanos que los lleva a conducirse de manera degradada, "cuantitativa», y a concebirse como simples útiles de trabajo, Goldmann da cuenta de la existencia de dos estructuras, la del género novelesco y la del intercambio económico, que se vuelven, a su parecer, homólogas. Goldmann asume que ha tenido lugar una transformación de la novela a partir de Kafka y de los análisis marxistas de la reificación, pero conviene también en que para los sociólogos de la literatura eso plantea un problema más que una explicación: si es evidente que el mundo absurdo de Kafka o de L'Étranger (1942) de Camus, o el mundo compuesto de objetos relativamente autónomos de Robbe-Grillet, se corresponden con el análisis de la reificación tal como ha sido desarrollado por Marx y los marxistas ulteriores, la cuestión sería saber por qué, si dicho análisis se elaboró durante la segunda mitad del siglo XIX y concierne a un fenómeno cuya aparición se sitúa incluso antes, este fenómeno no se manifestó en la novela más que a partir de la Primera Guerra Mundial (Goldmann, 1964: 34). Dicho de otro modo: la novela representa «la transposition sur le plan littéraire de la vie quotidienne dans la société individualiste née de la production pour le marché» (Goldmann, 1964: 36), y su comple- 
jidad formal no es más que un intento por estetizar la complejidad que vive a diario el ser humano en una sociedad regida por los intereses tiránicos del valor de cambio ${ }^{6}$.

De ello se deriva que la novela como género no puede ser la expresión de una experiencia puramente individual, sino que, por el contrario, ha nacido y se ha desarrollado solo en la medida en que un descontento no conceptualizado, una aspiración afectiva proyectada hacia los valores cualitativos -aquellos que se asocian con el valor de uso (individualidad, artesanía, originalidad, necesidad, etc.)-, ha emergido también en el conjunto de la sociedad -o tal vez únicamente entre las capas medias, de donde provienen la mayoría de los escritores (Goldmann, 1964: 48). La contradicción entre estos dos axiomas que propone Goldmann de forma consecutiva -por una parte: la dinámica reificadora del capitalismo, al estar anclada en la vida económica, es totalizadora y totalizante; y, por otra: la obra de arte, en tanto que expresión de malestar, supone una negación de la realidad cuantitativa impuesta y de sus mediaciones- se resuelve parcialmente en la persona del artista: a pesar de estar constantemente amenazada por la reificación, cuya acción es general en el conjunto de la estructura social, la creación cultural no cesa porque los escritores son «individus essentiellement problématiques» (Goldmann, 1964: 47) que subsisten aferrados a los valores cualitativos en el seno de la sociedad mercantil (aunque sin poder sustraerse por completo a la degradante existencia cuantitativa).

Esta condición hasta cierto punto discordante del sujeto creador hace que su creación, la novela, surja -al menos en lo que, siguiendo a Lukács, se considera su primer periodo, previo al modernismo- como resultado de la contradicción entre el individualismo como valor universal engendrado por la sociedad burguesa y las importantes limitaciones que esa sociedad aporta en realidad a las posibilidades de desarrollo de los individuos (Goldmann, 1964: 48). Fruto de la inadaptación a su contexto que sufre la personalidad del escritor, la resistencia de la novela moderna a sumergirse por entero en el proceso de reificación sería justamente la prueba flagrante de lo que Goldmann denomina las «vertus transformationelles» de la literatura (Fabre, 2001: 25). Una de esas virtudes es la que consigue -mediante el ejercicio de la coherencia y gracias al acto creativo emanado de la individualidad excepcional del creador- que la conciencia colectiva se corresponda al máximo con la conciencia posible de los individuos y grupos en una situación histórica dada. Otra es la responsable de

\footnotetext{
${ }^{6}$ En este sentido, el alcance de la reificación es tal que, para Goldmann (1964: 44), la antigua teoría marxista según la cual el proletariado era el único grupo social capacitado para constituir el fundamento de una nueva cultura desde el momento en el que no estaba integrado en la sociedad reificada se ha demostrado - en vista de la ausencia de una verdadera oposición revolucionaria al sistema- errónea. Este hecho demostraría una vez más que la novela, más que una transposición imaginaria de las estructuras conscientes de un grupo social, es una búsqueda de valores que la vida económica tiende a hacer implícitos para todos los miembros de la sociedad.
} 
que la conciencia colectiva pueda inscribirse en una trayectoria progresista y de ruptura con la ideología dominante, trayectoria en la que la obra literaria representaría la expresión misma de dicha ruptura.

Hasta ahora, Goldmann ha venido ampliando los comentarios tempranos de Lukács sobre la forma novelesca sin contradecir el núcleo de los mismos. Sin embargo, se produce un cierto desacuerdo en torno a la esencia de la novela contemporánea -tanto la del primer periodo como la del segundo, que comentaremos a continuación- que lo acerca más a las posiciones adornianas sobre la naturaleza díscola del artista. Aun admitiendo, con Lukács, que la novela del héroe problemático tiene un origen inequívocamente burgués ${ }^{7}$, se percibe pronto cómo esta se convierte en una «forme de résistance à la société bourgeoise en train de se développer» (Goldmann, 1964: 52) de carácter fuertemente crítico y oposicional que no es en ningún caso la expresión de la conciencia real o posible de la burguesía. En realidad, con la excepción de Balzac, apenas se han desarrollado otras expresiones literarias importantes que acojan los valores conscientes y las aspiraciones efectivas de la burguesía ${ }^{8}$, y ello es así porque el pensamiento burgués, ligado como la sociedad burguesa a la existencia de la actividad económica mercantil, es precisamente el primer pensamiento de la historia radicalmente profano; el primer pensamiento cuya tendencia inherente es la de negar todo lo sagrado. La sociedad burguesa habría creado la primera forma de conciencia puramente aestética: el racionalismo, la característica esencial del pensamiento burgués, ignora en sus expresiones extremas la existencia misma del arte $-\mathrm{y}$ por eso, dice Goldmann, no han germinado las estéticas cartesiana o espinozista, por poner dos ejemplos de corrientes racionalistas, y el artista se convierte por lo general en un ser problemático y crítico con la sociedad (Goldmann, 1964: 55-56)․․

\footnotetext{
${ }^{7}$ En efecto, Goldmann suscribe la tipología de la novela establecida por Lukács en sus primeros trabajos, a saber: la novela del «idealismo abstracto», representada por Don Quijote (1605) o Le Rouge et le Noir (1830); la novela psicológica, cuyo exponente más claro sería L'Éducation sentimentale (1869); y la novela educativa, como lo sería Wilhelm Meister (1795). Esta clasificación, por cuanto subraya la preponderancia de los valores liberales, evidenciaría el origen burgués de la novela como forma y, en concreto, la necesidad de expresión de la experiencia personal del héroe (Lukács, 2010).

${ }^{8}$ En lo que concierne a la valoración de Balzac, Goldmann se adhiere a la línea clásica que va desde Marx y Engels hasta el propio Lukács. También para él Balzac sería la gran expresión literaria del universo estructurado por los valores conscientes de la burguesía: individualismo, sed de poder, dinero, erotismo que triunfa sobre los antiguos valores feudales del altruismo, la caridad y el amor, etc. (Goldmann, 1964: 53).

${ }^{9}$ Estas aseveraciones un tanto tajantes, que desde luego convendría contrastar, rebaten no solo la posición, ya conocida, de Lukács, sino también la de Henri Lefebvre, un pensador marxista coetáneo a Goldmann y con quien el debate era habitual. Aunque considera que «l'art ne se réduit ni à une connaissance confuse, ni à une connaissance ou une idéologie appliquées», porque es una superestructura, Lefebvre, más tradicional, mantiene que la novela es la forma de expresión adecuada de la sociedad
} 
La explicación que acabamos de dar es la que le permite a Goldmann argüir que no existe una «vision du monde» burguesa que se haya materializado en las obras literarias de la época histórica correspondiente. De este modo, Goldmann estaría refutando la perspectiva lukácsiana, que sin embargo es absolutamente central en su pensamiento, que encontraba en las obras de los realistas clásicos - por descontado burgueses- la mejor radiografía de la totalidad, a partir de la cual es posible visualizar y comprender las tendencias intrínsecas de la sociedad. Pero si, en realidad, según Goldmann estas obras de los realistas clásicos no consiguen articular una visión del mundo, va de suyo que no son suficientemente competentes para profundizar en las intrincadas relaciones entre los grupos sociales y se limitan a describir los aspectos meramente inmediatos de la realidad. De todos modos, en el fondo, se trata de la conclusión o derivación que le es inmanente a una postura metodológica, en cierto sentido elitista, desde la cual se oye resonar todavía el eco de Lukács: la noción goldmanniana de coherencia -que es lo que fundamentalmente persigue Goldmann con su análisis de las obras literarias ${ }^{10}$ - precisa de tanto rigor que termina convirtiéndose en un filtro que excluye del análisis sociológico a un gran número de obras que no se consideran merecedoras, desde la posición subjetiva del crítico, de atención analítica. A causa de su supuesta falta de coherencia, las obras «de niveau moyen» no pueden expresar un verdadero universo preciso y unitario. Solamente «les grands écrivains» logran crear un universo imaginario coherente cuya estructura corresponde a aquella hacia la que tiende el conjunto del grupo (Goldmann, 1964: 345). Y solo así, en virtud de este criterio tan estricto o reduccionista, se entiende, de hecho, que exista para Goldmann un número tan limitado de visiones del mundo. Podría decirse, por tanto, que el edificio teórico goldmanniano se apoya de algún modo en ciertos juicios de valor que buscan sostener la hipótesis de que la "grandeur culturelle» (Fabre, 2001: 25) -y aquí se recupera el recuerdo de Lukács, a quien podían leérsele expresiones similares- se tiene que caracterizar por los más altos niveles de coherencia.

\subsection{Vanguardia de «l'absence», vanguardia de la «présence» y realismo}

Goldmann considera que las creaciones literarias vanguardistas o modernistas ofrecen, a través de la enunciación de la experiencia subjetiva del individuo, informaciones valiosas sobre la evolución del mundo contemporáneo. Esta tesis lo lleva a rechazar, por estrecha, la visión lukácsiana (cuya obstinación contra el irrealismo de

burguesa y que incluso puede «rebondir comme forme d'expression des luttes prolétariennes, de la construction du socialisme, de la vie socialiste» (Lefebvre, 2001: 85-86).

${ }^{10}$ El propio Goldmann postulaba que «es la coherencia interna del texto lo que le permite sobrevivir» (citado en Sasso, 1976: 19), es decir, lo que facilita su transmisión, ya que en cada uno de los textos se lleva a cabo un acto de creación literaria. No en vano, existe un consenso académico en que "le structuralisme génétique teste la cohérence interne d'un roman» (Fabre, 2001: 21). 
las formas «decadentes», además, deja de tener sentido una vez se ha refutado, como hace Goldmann, la teoría del reflejo) ${ }^{11}$. El análisis efectuado en Pour une sociologie $d u$ roman sobre la novela y los escritores del primer periodo se hace extensivo a la literatura de vanguardia, que Goldmann bautiza como «les deux avant-gardes» por las razones que expondremos en seguida: siendo creadores preocupados por el valor de uso del producto, los artistas de la vanguardia intentan escapar a la primacía del valor de cambio propia del capitalismo (Goldmann, 1964: 25), pero sus intentos tropiezan con la imposibilidad de expresar una conciencia colectiva, ya que su búsqueda de valores no está defendida por ningún grupo social. La afirmación de que la búsqueda de valores de la novela contemporánea del segundo periodo no representa la conciencia posible de ningún grupo social encaja con la idea, sostenida por Escarpit y Lefebvre (1969: 22 y 122), de que la vanguardia nace para desesclerotizar una situación estética determinada poniendo en tela de juicio los valores burgueses. Pero, al surgir en y desde el seno mismo de la sociedad burguesa, sus mensajes de disconformidad solo le llegan a una élite reducida, a diferencia de lo que sucede con la cultura de masas. Por eso la literatura modernista «n'aurait plus de valeur propre, positive, productive» (Fabre, 2001: 25), lo que para Goldmann (1964: 52) significa que dicha literatura abandona todo intento de reemplazar al héroe problemático y a la biografía individual -características iniciales de la novela- por otra realidad novedosa.

En otras palabras: los escritores vanguardistas se esfuerzan por escribir la novela de la ausencia de sujeto, que es asimismo la de la inexistencia de una búsqueda susceptible de progresar. Esta quietud ontológica de la novela modernista no puede sino despertar la reminiscencia de esa literatura que según Adorno participaba apolíticamente de lo político ${ }^{12}$. Goldmann precisa los términos: la vanguardia-desde Kafka,

\footnotetext{
${ }^{11}$ En el ensayo-conferencia que pronunció en 1964 en el homenaje a Kierkegaard de la UNESCO, Goldmann declara: «Aunque mi admiración por la obra de Lukács es muy grande, no me es posible seguirle en su apreciación de la vanguardia del siglo XX; [...] aunque fue uno de los primeros en percibir la crisis de la sociedad europea occidental, nunca ha abandonado la esperanza de que los valores positivos del humanismo clásico se realicen próximamente [...], y no ha sido capaz de comprender los aspectos positivos que $[\ldots]$ han podido encerrar las actitudes negativas, las oposiciones y las críticas radicales» (apud Martín, 1971: 177).

${ }^{12}$ Pierre V. Zima, representante de la corriente sociocrítica y antiguo alumno de Goldmann, desarrolla en Pour une sociologie du texte littéraire (1978) -título que a su vez recuerda al que eligió su maestrouna interesante relectura de la teoría adorniana aderezada con las aportaciones de Jan Mukařovský, integrante de la Escuela de Praga. Basándose en el doble carácter del texto (autónomo y fait social), el crítico afirma: «Ce n'est pas la question: Que dit le texte? que devrait se poser le sociologue mais la question: Comment dit le texte? (au niveau narratif, syntaxique, etc.). C'est sur le plan du comment de l'écriture que se manifeste le sens social» (Zima, 2000: 56). Sorprende el nivel de similitud con un comentario del Lukács temprano: «El defecto mayor de la crítica sociológica del arte consiste en que busca y analiza los contenidos de las creaciones artísticas, queriendo establecer una relación directa
} 
Beckett y Ionesco hasta Sarraute, Duras o Robbe-Grillet- se define por el hecho de que su contenido esencial, el denominador común de las obras que la conforman, está constituido por la ausencia «de l'essentiel, absence de tout ce qui pourrait être important pour la vie et l'existence des hommes» (Goldmann, 1970: 168). O sea, los escritores de la vanguardia expresan sobre todo no valores realizados o realizables, sino justamente su vía negativa, «l'impossibilité de formuler ou d'apercevoir des valeurs» (Goldmann, 1970: 172). Lo que Lukács veía de forma peyorativa en la vanguardia pierde en Goldmann, en este asunto en concreto, la rémora del juicio de valor, puesto que, una vez más como Adorno, considera que la vanguardia ofrece, en realidad, «une perspective réaliste sur la société industrielle occidentale» (Goldmann, 1970: 186) porque refleja la deshumanización de la vida social, cuyos aspectos más importantes desde el punto de vista goldmanniano son la pasividad, las auto-regulaciones, la desaparición progresiva de los aspectos cualitativos de la existencia y, a partir de ahí, el bloqueo particularmente potente de las fuerzas motrices de la transformación histórica.

En este punto de la reflexión, la apelación al supuesto realismo de las vanguardias invita a pensar que la definición de realismo es potencialmente aplicable a cualquier corriente artística, y eso, más que delimitar ciertas características de un estilo, puede acabar desdibujando toda pretensión de utilidad, claridad y distinción del análisis. Es más, Goldmann no define el realismo en función de criterios estéticos o en función del mayor o menor grado de proximidad de una obra respecto al ideal de la mímesis, sino - desde una posición que aspira a ser sociológica y con un vocabulario que le es usual- como la "création imaginaire d'un monde dont la structure est homologue à la structure essentielle de la réalité sociale au sein de laquelle l'œuvre a été écrite» (Goldmann, 1970: 186). En este sentido, a pesar de haberse desembarazado de la acritud hacia las vanguardias, sigue otorgándole un valor positivo y ejemplar al realismo, cuya quintaesencia se encuentra para Goldmann en el «nouveau roman", y más concretamente en los trabajos de Robbe-Grillet, que son el paradigma de un «réalisme implacable» (Goldmann, 1970: 172). Así las cosas, la forma literaria - «un ensemble de microstructures sémantiques, sémiologiques, phonologiques, etc.» (Goldmann, 1966: 133) - se caracterizaría, antes que por ajustarse a los parámetros tradicionales de un estilo (sea realista o no), por estar en relación funcional, más o menos compleja pero siempre formulable, con la estructura global del universo de la obra (lo cual remite a una visión del análisis literario que tiende a despegarse de las

entre ellos y determinadas condiciones económicas. Pero lo verdaderamente social de la literatura es la forma. Solo la forma consigue que la vivencia del artista con los otros, con el público, se convierta en comunicación, y gracias a esta comunicación establecida, gracias a la posibilidad del efecto y la aparición verdadera del efecto el arte llega a ser -en primer lugar- social» (Lukács, 1968: 67). 
cuestiones específicas de la escritura en favor de la captación general de los aspectos sociológicos que, en todo caso, traslucen a través de la forma ${ }^{13}$ ). Y, en fin, dado que la literatura modernista puede ser en sí misma realista, lo opuesto a la vanguardia de la ausencia en términos de valores no es el realismo crítico o socialista, como defendía Lukács, sino otra vanguardia preocupada precisamente por «la présence de forces de résistance à la réification et d'action qualitative menée dans le sens du devenir de l'histoire» (Goldmann, 1970: 186) ${ }^{14}$. Goldmann admite que se trata, no obstante, de una teorización que no se respalda en la práctica, ya que no habría creaciones literarias de importancia - nuevamente según el estricto criterio goldmanniano- que incluyan valores humanistas y que puedan ponerse de momento a la altura de los autores modernistas antes citados.

El desarrollo de la estética lukácsiana en la sociología de la literatura de Goldmann revela hasta qué punto la perspectiva hegeliana adoptada, favorable a la coherencia y a la totalidad histórico-estética, engendra un pensamiento monológico que impone la exigencia clasicista de la coherencia hasta a las obras de vanguardia, lo cual llega a granjearle una discusión con Adorno a propósito de Beckett (Zima, 1999: 22-23). En un coloquio sobre sociología de la literatura celebrado en Royaumont en enero de 1969, los dos pensadores cruzan algunas palabras en relación a la obra de Beckett, que para Goldmann «intègre les antagonismes, les difficultés, les brisures dans une visión malgré tout globale du monde qui peut être réduite en système». Adorno, que considera el fragmento "comme une forme», opina sin embargo que el arte de vanguardia es necesariamente contradictorio, fragmentario e inacabado, es decir, abierto; por lo que proyectar el postulado hegeliano y clasicista de la completitud y la autosuficiencia sistémica de una obra resulta inaceptable en el contexto de la discusión contemporánea sobre la vanguardia (Goldmann y Adorno, 1973: 540).

\footnotetext{
${ }^{13}$ Pero, aunque sea quizás la cuestión de la que menos se ocupa Goldmann en el conjunto de su obra, la expresión literaria y la forma no carecen de importancia para él. Sus estudios sobre Pascal revelan, por ejemplo, que la paradoja es el gran medio de expresión de su visión del mundo: «Il est évident que l'équilibre et le balancement parfait des deux temps du Cogito ergo sum ou des deux temps du "Je pense donc je suis", expriment à merveille l'optimisme et l'équilibre de la philosophie cartésienne, tandis que la montée verticale du premier élément et la chute brusque de la fin dans "Le silence éternel des espaces infinis m'effraie”, concentrent et expriment l'essence même de la vision tragique» (Goldmann, 1970: 112-113). La visión trágica parte de la idea de que el ser humano es al mismo tiempo "grand et petit», es decir, que el sujeto no puede definirse sino a través de dos atributos en apariencia contradictorios.

${ }^{14}$ Pese a que Goldmann quiera hacer pasar su definición de los valores positivos de la vanguardia de la presencia por una definición original o autónoma, ¿acaso no pueden reconocerse en ella plenamente las aspiraciones humanistas de Lukács, quien depositaba en el realismo crítico y en el realismo socialista justamente los mismos anhelos (combate de la alienación, progreso, racionalidad, cientificismo, etc.)?
} 


\section{La teoría de la producción literaria de Pierre Macherey}

\subsection{Autonomía y dependencia: ajustando cuentas con sus contemporáneos}

Con la publicación de Pour une théorie de la production littéraire (1966) Pierre Macherey aspiraba de algún modo a responder con una determinación integradora y concluyente a muchas de las cuestiones expuestas por varios de sus compatriotas a tenor de las diferentes teorías materialistas de la literatura que se habían venido examinando hasta entonces. Su propuesta, centrada en elucidación de la «chose littéraire», no cede a la tentación de hacer de la literatura la expresión de una intencionalidad autorial, de la visión del mundo de un grupo social o de un inconsciente productor (como avanzaba el psicoanálisis), ni se conforma con posicionarla como un simple elemento de la superestructura. La ambigua expresión «chose littéraire» pretende definir y subrayar el carácter dual de la literatura:

Es [...] lo que explica objetivamente cómo algo como la literatura puede o ha podido ser producto, lo cual implica que se tome en cuenta el conjunto de las condiciones materiales, históricas y sociales de esta producción. Pero es también, en segundo lugar, indisociablemente, lo que produce la literatura propiamente, es decir, el conjunto de efectos, de producciones $\mathrm{y}$, sobre todo, de producciones de significado de las que, en tanto que tal, ella es potencialmente portadora, pero de la que no se deducen mecánicamente causas a las que deba reportar su producción en el primer sentido de la expresión (Macherey, 2009: 122).

Evitando incurrir en una reducción a lo singular (el autor) o en una reducción a lo colectivo (el contexto), Macherey hace del texto literario el resultado, jamás definitivo, de un proceso de producción. Tal premisa obliga a desposeer al autor del papel romántico que le atribuía una genialidad más o menos innata y a reconocerlo, en cambio, como un productor a la manera benjaminiana. Según el propio Macherey, ello polemiza abiertamente con la postura que sostenía el «filósofo oficial» del PCF por aquel entonces, Roger Garaudy, quien, con su teoría del «réalisme sans rivages», se enreda en una retórica místico-religiosa -que Macherey (1966: 71) apoda despectivamente «la religion de l'art», «les spéculations sur l'homme créateur»- desde la cual la creación permanece vagamente inexplicada y es vista como «une irruption, une épiphanie, un mystère». Garaudy (1963: 57) sostiene que, en lugar de ser un mero prolongamiento de los deseos primitivos y de las necesidades básicas de la especie, como lo sería el trabajo animal, lo peculiar del trabajo humano -y, según se sigue, del arte- reside en que «n'est jamais copie de la nature mais création selon une loi 
spécifiquement humaine», posición que a todas luces se ampara en las tesis de $\operatorname{Marx}^{15}$. Para este pensador no existe la oposición de principio idealista según la cual el trabajo estaría necesariamente sometido a las exigencias vitales serviles, mientras que la creación artística sería pura libertad y juego (la «finalidad sin fin» de Kant). Solamente en la sociedad de clases, en la cual reina el trabajo alienado, tiene lugar esta escisión del acto primitivamente único del trabajo, puesto que el trabajador no realiza sus fines propios, sino aquellos que le son asignados por el propietario de los medios de producción, quedando mutilada de este modo la dimensión propiamente humana del trabajo (Perottino, 1974: 37-38). Se trata de una reflexión claramente influida por los comentarios de Marx sobre la enajenación del trabajo en los Manuscritos de economía y filosofia $(1844)^{16}$.

Así pues, para Garaudy el realismo no tiene por qué implicar el triunfo de lo verosímil, sino que comporta, en un amplio sentido, una actitud: la de la toma de conciencia de esa participación en la creación continuada del ser humano para sí mismo, que es la forma más elevada de libertad. Se trata de una consideración que, desde la imprecisión propia de la argumentación humanista, deja sin desarrollar la idea que Macherey juzga fundamental: que la obra literaria es un proceso real de trabajo que nace en y de unas condiciones materiales determinadas. El principal motivo de divergencia se encuentra en la estructura «circulaire, tautologique (tout par l'homme, tout pour l'homme), [...] profondément réactionnaire» (Macherey, 1966: 70) de la ideología humanista esgrimida en última instancia por Garaudy: a pesar de que ambos defienden la tesis, latente en la estética lukácsiana tardía, de que el arte no es sino una forma de trabajo, la imagen del «homme-dieu» que se desprende la tesis

\footnotetext{
${ }^{15}$ Concretamente, Marx defiende una concepción de trabajo que incorpora tres dimensiones: la actividad orientada a un fin (dimensión cognitivo-instrumental o teleológica), la interacción social y comunicación (dimensión práctico-moral o social) y la autoexpresión práctica del ser humano (dimensión estético-expresiva). Lejos de contener una simple glorificación del trabajo o una noción productivista del mismo, la obra de Marx abandera la potencial «autorrealización activa» del ser humano a través del trabajo (esto es, la sensación de autosuperación y desarrollo de las capacidades, que puede significar esfuerzo pero también goce). El trabajo es la precondición material de la existencia humana, pero se trata de una constatación empírica para Marx, y de ahí no se deriva que el trabajo sea fuente de toda riqueza, de toda moral o de todo progreso. Su prioridad era el desarrollo humano, con el fin de que el ser humano domine y controle la producción, en vez de verse controlado por ella: Marx solía despreciar el goce de la acumulación para oponerlo a la acumulación de goces (Noguera, 2011: 171-173).

${ }^{16}$ Esta perspectiva encuentra en general muchas similitudes con la sostenida por Fischer (1970: 99104), quien también caracteriza la actividad artística como un trabajo creador más libre que, al favorecer el desarrollo de la personalidad humana, sobrepasa el terreno de la producción material (necesidad) y se instala más cerca del «reino de la libertad», lo cual vuelve a remitir al último Lukács.
} 
garaudiana por la cual la creación artística opera como vehículo de la subjetividad humana resulta profundamente alienante ${ }^{17}$.

Tampoco la «littérature engagée» que propugnaba Sartre escapa a la revisión de Macherey. Desde el enfoque sartreano, el compromiso intersubjetivo de una obra con su época reviste de un carácter absoluto el acto literario: el autor sacrifica a su «época» su propio deseo de inmortalidad (ensońación esta última típicamente burguesa para Sartre). En un fragmento titulado "Écrire pour son époque» de Qu'est-ce que la littérature, finalmente desechado, Sartre es explícito en este sentido: «Un livre a sa vérité absolue dans l'époque [...]. C’est une émanation de l'intersubjetivité, un lien de rage, de haine, ou d'amour entre ceux qui l'ont produit et ceux qui le reçoivent» (apud Contat y Rybalka, 1970: 673). Macherey (2014: 48) observa que la estética sartreana es esencialmente hegeliana porque retoma la idea presente en la Fenomenología del Espíritu (1807) según la cual el arte mantiene una relación privilegiada con los tiempos pasados porque, en sí, este siempre se hace para los tiempos "qui sont destinés à devenir révolus", siendo eso mismo lo que le concede importancia a su presente (Hegel, 1991: 489). En suma, según Sartre, la literatura funciona sabiendo que, para hacer resonar al máximo su potencialidad política, debe renunciar a reproducirse en otras condiciones distintas a las de su origen. A su vez, al sacrificio del autor le responde el compromiso del lector, que asume una posición histórica y lee el texto atendiendo a su contexto de origen con vistas a poder restituir su significado auténtico.

Macherey describe la actitud sartreana como una "poétique de l'identification et de l'adhésion» bastante romántica que presupone la colaboración simultánea del autor y del lector -uno en el plano de la producción (escritura) y otro en el plano de la reproducción (lectura) - en la atribución del significado de la obra. Existiría, pues, una identidad entre el acto de la lectura y la libertad creativa del autor que acaba convirtiendo la emergencia del texto en un acto creador común (Macherey, 2014: 4749). Frente a esta posición un tanto voluntarista, Macherey se alinea con el Foucault

\footnotetext{
${ }^{17} \mathrm{La}$ aversión que muestra Macherey hacia el humanismo procede del que fuera su maestro, Louis Althusser. El filósofo consideraba que existía una «inégalité théorique frappante» entre el concepto de socialismo, y todo lo que este encarna, y el de humanismo. El primero es de naturaleza científica porque, con Marx, rechaza los clásicos debates sobre la esencia humana, que son reemplazados por una teoría de los diferentes niveles específicos de la práctica humana (económica, política, ideológica, científica) fundada sobre las articulaciones de la unidad de la sociedad humana. El segundo es de naturaleza ideológica por cuanto reproduce los juicios de valor del individualismo burgués para el que todos los seres humanos son, sin distinción, libres (Althusser, 1977: 229-249). Véase el capítulo «Marxisme et humanisme» en Althusser (1977). Además, Althusser señala asimismo que expresarse en los términos de "creación», «creador», etc. forma parte del lenguaje «espontáneo», es decir, ideológico (Althusser, 1968: 10).
} 
del prefacio de Histoire de la folie (1961), para quien el discurso es concebido ante todo como un acontecimiento. De este modo, las obras no son simplemente "producidas» como tales de una vez y para siempre en un lugar y en un tiempo determinados, sino que comienzan a existir a partir del momento en el que son «reproducidas» en las múltiples lecturas que se hacen de ellas: "chaque lecture lui donne, pour un instant, un corps impalpable et unique» (Foucault, 1972: 7), apareciendo así una infinidad de posibilidades de variación del discurso. Esta posición se halla profundamente influida por la lectura de las Ficciones (1944) de Borges, y particularmente por lo manifestado en el popular relato "Pierre Menard, autor del Quijote», donde el tema de la cita, la reescritura o la reproducción se constituye como un modelo de escritura en sí mismo que revela la no identidad de lo repetido, o sea, la historicidad del texto. Continuando el razonamiento, Foucault publicará algunos años después la famosa conferencia "Qu'est-ce qu'un auteur ?» (1969), donde expone que la función de autor es un efecto del discurso y, como tal, no universalizable; argumentos que, junto con los de Barthes en «La mort de l'auteur» (1967), dibujan la famosa muerte del autor.

En cuanto a Goldmann, Macherey desmonta buena parte del núcleo sociológico de su proyecto teórico al criticar la idea misma de la existencia de un sentido inmanente de la obra (o, lo que es lo mismo, la concepción de que la obra es el producto de una intención unitaria, sea esta objetiva o subjetiva, consciente o inconsciente); crítica que, desde luego, bien podría inspirarse en la noción de «verdad no intencional» desarrollada por Benjamin a partir de Husserl y secundada después por Adorno. En su tesis El origen del drama barroco alemán (1928) es donde Benjamin (1990: 18) sostiene que «la verdad es un estado no intencional del ser, configurado por las ideas», queriendo significar con ello que los significados subjetivos atribuidos por el sujeto a su propia obra no tienen por qué agotar ni coincidir con su contenido esencial, ya que la actividad artística se despliega en un contexto histórico-social abierto y heterogéneo que no depende exclusivamente del sujeto y está abierta a un horizonte de significaciones y funciones sociales no previstas e incluso imprevisibles (Mayorga, 1982: 121). Por necesario que sea destacar el influjo que sobre los escritores ejercen los grupos sociales, los cuales contribuyen a fijar las grandes orientaciones de las obras, la teoría de Goldmann adolece de una «certaine imprécision» (Macherey, 2013: 15) cuando se trata de hacer frente a la diversidad que está presente de forma innegable en ellas, sobre todo teniendo en cuenta que «la Historia es un proceso sin telos ni sujeto" (Althusser, 1974: 98), premisa que también hace suya Macherey y que pone contra las cuerdas integralmente a Goldmann.

En efecto, es el autor literario quien decide sobre la obra, pero su decisión está determinada por el hecho de que es, a su vez, su primer lector: la escritura es ya lectura y la decisión del escritor es, entonces, "l'illusion d'un choix», puesto que el movimiento del relato o de la narración depende de una causalidad propia -apreciación 
que remite, otra vez, a Adorno- que el propio escritor va descubriendo (y tal vez reformando o modificando) a medida que lee (Macherey, 1966: 54). Para Macherey, la obra literaria no es la realización de una necesidad inmanente, sino, al contrario, un producto más bien aleatorio de motivaciones contradictorias que es conveniente delinear (Sasso, 1979: 16). Además, con el empleo del término "coherencia», Goldmann está defendiendo implícitamente el postulado de la unidad de la obra, el cual reconoce por lo general la existencia de un sentido definitorio de esa unidad. Pero, en opinión de Macherey (1966: 80), "plutôt qu'une plénitude idéale et illusoire», lo que en realidad se manifiesta en la obra son "plusieurs sens» que demostrarían que lo literario se erige como un artefacto incompleto e informe, nunca autosuficiente ${ }^{18}$. Asumiendo que la obra nunca detenta, más que en apariencia, la cohesión de un todo unificado y predeterminado -como mucho revela una suerte de «nécessité libre [...] à la rencontre de plusieurs lignes de nécessité»-, Macherey sugiere que los relatos o novelas de aventuras, al estar llenos de imprevistos, son como una alegoría de la obra literaria en general (Macherey, 1966: 48-49). Por tanto, la tarea de la crítica literaria no es la de "achever le livre», sino la de instalarse en su incompletitud "pour en faire la théorie» (Macherey, 1966: 84) -posición que revela la influencia que sobre Macherey ejercen los planteamientos de Barthes en Essais critiques (1964) y Critique et vérité (1966), en particular la idea de que a la crítica no le corresponde «descifrar el sentido de la obra estudiada, sino reconstruir las reglas y las sujeciones de elaboración de este sentido» (Barthes, 2002: 350). Para eso es necesario deshacerse de ciertas convenciones que Goldmann, entre otros, estimula: el postulado de la belleza (la obra se compone conforme a un modelo), el postulado de la inocencia (la obra se basta a sí misma y, con la institución misma de su discurso, suprime todo recuerdo de lo que no es ella) y el postulado de la armonía o la totalidad (la obra es perfecta, acabada, completa) ${ }^{19}$.

En el fondo, la crítica de Macherey a sus contemporáneos encubre una vez más ciertas discrepancias surgidas en el debate concerniente a la autonomía formal la literatura, hecho que todos de una forma u otra ya admitían e intentaban explicar de acuerdo con sus propios parámetros. La apuesta de Macherey pasa, ciertamente, por

\footnotetext{
${ }^{18}$ El combate de Macherey contra la ilusión de totalidad en la literatura recuerda a la apreciación hecha por Adorno en Minima moralia (1951): «El todo es lo falso» (Adorno, 1998: 48).

${ }^{19}$ Macherey se muestra especialmente descontento con la función adquirida por la crítica literaria, la cual, mediante la utilización de un lenguaje nuevo, hace resonar una diferencia respecto a la obra tal y como era concebida por el autor: «La critique prétend traiter l'œuvre comme un produit de consommation: ainsi elle tombe aussitôt dans l'illusion empirique puisqu'elle se demande seulement comment recevoir un objet donné. Cependant, cette illusion ne vient pas seule: elle se double aussitôt d'une illusion normative. La critique se propose alors de modifier l'œuvre pour pouvoir mieux l'absorber» (Macherey, 1966: 40). Para un acercamiento a esta "crítica de la crítica», por tomar la expresión que da título a la obra de Todorov, véase Delaveau y Kerleroux (1970).
} 
el reconocimiento de que el texto literario posee o contiene una verdad propia. Amén de ostentar la cualidad de ser el producto de un trabajo particular, su especificidad es precisamente su autonomía -la obra "est à elle-même sa propre règle, dans la mesure où elle se donne ses limites en les construisant» (Macherey, 1966: 57)-, la cual radica, como se detallará más tarde, en el uso inédito que hace en su propio seno del lenguaje y de la ideología, «les arrachant d'une certaine façon à eux-mêmes pour leur donner une nouvelle destination, les faisant servir à la réalisation d'un dessein qui leur appartient en propre» (Macherey, 1966: 57). Con todo, esa estrecha relación con el lenguaje desvela también paralelamente un estado de dependencia (que en ningún caso contradice la proclama de autonomía): como todo producto, la literatura es una "réalité seconde» que se subordina, por ejemplo, a los diferentes usos teóricos e ideológicos del lenguaje, a la historia de las formaciones sociales, al propio estatuto del escritor (así como a los problemas que le acarrea su existencia personal) y, en definitiva, al resto de la historia de la producción literaria, que le transmite los instrumentos esenciales de su trabajo (Macherey, 1966: 59).

\subsection{Producción y reproducción literaria}

La investigación de Macherey que suscita las enmiendas referidas en el apartado anterior y que tiene por objeto el esclarecimiento del hecho literario comienza con una pregunta: ¿cómo pueden las obras, producidas en un momento histórico preciso y dependientes de un condicionamiento social e ideológico determinado, suscitar un interés transhistórico en apariencia independiente de esa situación temporal? ${ }^{20}$ Es decir, dado que la obra literaria «n'est pas seulement l'expression d'une situation historique objective, qui l'attribuerait une fois pour toutes, avant même qu'elle soit faite, à un public déterminé» (Macherey, 2014: 73), resulta absolutamente pertinente fundar una teoría de la lectura «qui permît de comprendre comment et pourquoi des œuvres de la littérature, en dépit du fait qu'elles sont élaborées dans et pour leur temps, sont en mesure de vivre au-delà de lui, dans des conditions qui sont celles, non de leur simple production, mais de leur reproduction, qui leur communique une dimension dynamique» (Macherey, 2013: 22). Así, aunque las condiciones de producción de una obra generan sus propias formas de comunicación, esta no se cierra sobre sí misma en los estrechos límites que traza alrededor de ella una lectura inmediata: la pervivencia temporal de la literatura viene dada por el pacto o contrato subjetivo que se produce entre el lector y el libro. Para consagrarse a la actividad de la

\footnotetext{
${ }^{20}$ La reflexión que motiva dicho interrogante se encuentra, por cierto, en los ya mencionados Grundrisse de Marx (1857: 62): «La dificultad no está en comprender que el arte griego y la epopeya están ligadas a ciertas formas de desarrollo social. La dificultad reside en el hecho de que nos procuran todavía placer estético y que tienen todavía para nosotros en ciertos aspectos el valor de normas y de modelos inaccesibles».
} 
lectura, el lector -que «entre dans le livre comme dans un monde différent»- debe admitir un cierto número de presupuestos implícitos o explícitos. En el horizonte de tal compromiso todo estaría permitido, e incluso lo arbitrario sería verídico (Macherey, 1966: 72-73). Como se ha podido ya intuir, la teoría de la producción de Macherey es también una teoría de la crítica y de la comunicación o recepción. El interés demostrado por el papel activo del lector, quien recupera y se apropia en su lectura de la vigencia del texto, está en sintonía con lo que sostenía Jauss también por aquellos años en La historia de la literatura como provocación (1970): la conciencia histórica del lector no existe como una posición inamovible, sino como un horizonte de expectati$\operatorname{vas}^{21}$.

Una teoría como la de Macherey, cuyo afán reside en el esclarecimiento de la «absence déterminée» constitutiva de las obras, se ampara asimismo en aquello que Kristeva denominaba entonces intertextualidad, a partir de la cual la originalidad de las obras se define siempre atendiendo a relaciones de influencia literaria: "On n'écrit jamais, sinon en rêve, sur une page complètement blanche: la réalisation d'un texte s'appuie nécessairement sur la reproduction de textes antérieurs, auxquels elle se réfere implicitement ou explicitement» (Macherey, 2014: 55). En la noción de ausencia determinada Macherey condensa la idea de que es la presencia alusiva de otros textos lo que permite una lectura actualizada de las obras, puesto que, al construirse necesariamente contra otros textos, los libros no se edifican sobre la prolongación de un sentido, sino a partir de la incompatibilidad de muchos sentidos, hecho que favorece una confrontación constantemente renovada con la realidad.

Al mismo tiempo, como discípulo y colaborador de Althusser, Macherey considera que lo que la literatura deja ver no son el mundo, el alma humana o la vida social de una época como tales, sino el cuerpo de representaciones a través de los cuales esas «realidades» son inmediatamente percibidas, siempre parcialmente y de manera deformada, lo cual se debe al hecho de que esas representaciones están al servicio de intereses particulares. La literatura no sería una representación más, sino una manera de poner en escena las representaciones ya impuestas por la historia. Su método persigue, en fin, una especie de reconstrucción hipotética de los materiales contenido, paradigmas narrativos, prácticas estilísticas y lingüísticas- que tuvieron que estar dados de antemano para que se produjera un texto particular en su especificidad única (Jameson, 1989: 47). En este sentido, uno de los motivos por los que en la obra de Macherey apenas se encuentran referencias suficientemente desarrolladas a las manifestaciones concretas de la literatura del siglo XX -a excepción de los comen-

${ }^{21}$ Resultan igualmente interesantes, por la relación que mantienen con el propósito de este trabajo, los comentarios que dedica Jauss en el cuarto capítulo de la obra mentada a las aporías de la estética marxista. Véase Jauss (2013: 160-168). 
tarios recurrentes sobre Borges, lo que destacan son sus estudios en torno a Verne, Tolstoi, Balzac y Robinson Crusoe (1719) - podría ser el hecho de que, más que interesarse por el grado y el tipo de contenido ideológico expresado mediante la forma literaria pre-modernista y modernista, Macherey se propone estudiar lo que, a través de su trabajo propio, produce realmente la literatura: a saber, no un doble de la realidad, como lo quiere la temática ordinaria de la superestructura, sino ciertas formas de intervención en el mundo que contribuyen a su Veränderung revolucionaria -puesto que dichas formas no se desarrollan en una suerte de mundo paralelo ocupado solamente por imágenes (sean estas verosímiles o no). El rol de Macherey, totalmente carente de juicios de valor respecto a las obras concretas, se orienta hacia la definición de la literatura en tanto que fenómeno ideológico propio de la superestructura pero mucho más material, complejo, escurridizo, contradictorio y vacilante que la caricatura que ha podido hacer de ella una cierta concepción mecanicista y simplificada de la teoría del reflejo. Lo que destaca de su tentativa -que ha influido tremendamente en Eagleton, Jameson y en la crítica anglosajona en general- es, justamente, esa voluntad por mostrar, más que ningún otro anteriormente, que las relaciones entre texto, ideología e historia son profundamente enrevesadas y no se trata, como lo quieren Lukács y Goldmann (con su alusión a las homologías), de que cada uno de estos niveles «refleje» de alguna manera los otros.

La intervención en el mundo a la que se aludía hace un momento se inscribe en la estética «saturada de experiencia» (Brecht, 2004: 173) de Brecht y de Benjamin, forzosamente práctica por cuanto, en lugar de preguntarse qué vínculo guarda cierta obra con las relaciones de producción propias de su época, se interesa por «cómo está en ellas» (Benjamin, 2012: 92): en efecto, al concebir la práctica literaria como producción, Macherey le atribuye a la literatura una función material que no es la de añadir una capa suplementaria a la esfera de la superestructura o perpetuar su funcionamiento idéntico, sino la de poner a prueba ese sistema más o menos coherente de representaciones que forma parte de la existencia colectiva, para «le faire éclater en ses disjecta membra, quitte ensuite à ramasser les morceaux pour en effectuer à distance, librement, la recomposition» (Macherey, 2013: 18). Lo que se busca son transformaciones reales, de efectos prácticos en sí mismos, ya sea en el modo de producción de los textos literarios y de las obras de arte o en el modo de su consumo social (Macherey y Balibar, 1974: 30). Así, en un pronunciamiento que recuerda al combate brechtiano contra la inercia de la catarsis aristotélica, Macherey (2013: 16-17) se inclina por «appréhender la littérature comme une activité et comme un travail, ce qui incitait à se débarrasser de la métaphore du "miroir", qui la confine dans un rôle contemplatif, passif en dernière instance, ou du moins à en affiner l'usage».

La fórmula lukácsiana del reflejo es de este modo desechada. Un capítulo concreto de Pour une théorie de la production littéraire («Lénine, critique de Tolstoï») está dedicado a la refutación de la teoría del reflejo (o, mejor dicho, a su afinamien- 
to), donde expone la cualidad consustancialmente tendenciosa o fragmentaria de la imagen literaria: «le rapport du miroir à l'objet qu'il réfléchit (la réalité historique) est partiel: le miroir opère un choix, sélectionne, ne réfléchit pas las totalité de la réalité qui lui est offerte» (Macherey, 1966: 118). Althusser (1968: 8) ya había apuntado en una ocasión que el arte no es en sentido estricto una forma de conocimiento -lo cual contradice la intersección fundamental que se produce entre la epistemología y la estética lukácsianas-, pero que no obstante mantiene una relación específica con el conocimiento. Macherey desarrolla esa premisa: la forma particular de conocimiento propia de la literatura no es de tipo contemplativo, ya que no se contenta con fotografiar la realidad para proponer visiones conformes (lo que le conferiría, en el mejor de los casos, un valor documental). Su «dimension de connaissance» revela las grietas que minan los sistemas perceptivos, interpretativos, ideales. Más que redoblar la relación imaginaria de los individuos con sus condiciones materiales de existencia (confirmando así las apariencias al revestirlas de formas prestigiosas que las hacen más fácilmente consumibles), la obra literaria despierta los interrogantes, mostrando las fallas y las inconsistencias (Macherey, 2013: 19). Esta perspectiva, desde donde se sienten los ecos de Adorno y de Brecht, y según la cual la literatura ayuda a ver las cosas de otro modo y a iniciar procesos de transformación, conduce, por un lado, a poner en valor la negatividad de la obra literaria (Adorno) y, por otro, propone una manera específica de actuar sobre el mundo en el mundo, en lugar de considerarlo a distancia como un espectáculo (Brecht).

Este acto de «bouleversement» epistemológico se realiza enteramente en el nivel de los enunciados que componen el discurso del escritor. No se trata, por tanto, de explicar el hipotético funcionamiento del reflejo de la realidad en la obra literaria, sino de identificar el sistema de producción que utiliza el escritor: ¿qué hace la obra con tales medios?, ¿para qué sirven?, ¿qué tipo de rigor instituye la lógica de las imágenes empleadas? (Macherey, 1966: 64). El lenguaje literario puesto en circulación en el texto, que supone un cambio de naturaleza respecto al lenguaje ordinario, activa un «mécanisme de l'illusion»: no hay literatura más que por la repetición y el desdoblamiento en forma de variación de los elementos de estilo. Lo que caracteriza a la literatura, para Macherey, es el uso especial del lenguaje en su vertiente paródica: imitando el lenguaje cotidiano (que es el lugar por excelencia de la ideología) y mezclándolo con enunciados "científicos», es a la vez conocimiento y caricatura de la ideología usual. En definitiva, el lenguaje no permite una reproducción de la realidad: «Il déforme plutôt qu'il n'imite» (Macherey, 1966: 65-66). Es algo muy similar a lo que sostenía Genette en «Frontières du récit» (1966): en la literatura no hay mímesis, sino diferentes grados de diégesis.

Los elementos que, reunidos, conforman un texto no sabrían tener realidad independiente: contrariamente al concepto científico, que es susceptible de desplazarse (de una teoría a otra), los elementos literarios están ligados a un contexto particu- 
lar, que define el único horizonte respecto al cual estos pueden ser leídos. Es en el entorno del libro donde adquieren su poder de sugestión y se vuelven representativos (Macherey, 1966: 50 y 62). Es decir, que el acto del escritor constituye un discurso y, en tanto que artificio del lenguaje, dicho discurso no puede estar referido a nada exterior: toda su verdad o su validez se encuentra cristalizada en la superficie del discurso, de forma que "la "réalité" indiquée par le livre n'est pas arbitraire mais conventionnelle: ainsi elle est fixée par des lois» (Macherey, 1966: 76). La realidad evocada en la obra es el resultado de una actividad de fabricación que se halla conforme a las exigencias de la obra, no de la realidad externa. Por ende, la ficción creada por la literatura no se puede definir simplemente como figuración (realista), como apariencia de una realidad, sino que es, de manera muy compleja, producción de una cierta realidad y de un efecto social; no es ficción sino "production de fictions» o, mejor aún, "production d'effets de fiction» y de los medios materiales para producirlos (Macherey y Balibar, 1974: 42). Son reflexiones sin duda muy próximas a las de Barthes sobre el "effet de réel» y el realismo como código de representación convencional. En $S / Z$, Barthes afirmaba que "ce qu'on appelle "réel" (dans la théorie du texte réaliste) n'est jamais qu'un code de représentation (de signification)». La cuestión de la representación se convierte en la cuestión de la verosimilitud: la referencia no posee realidad, lo real no es más que un código, una ilusión de discurso verdadero sobre el mundo real que podría llamarse «ilusión referencial». A su vez la referencia evocada por el texto es un producto de la intertextualidad, la «subtile immensité des écritures» (Barthes, 1970: 87 y 129).

\subsection{La obra literaria y el «langage de l'idéologie»}

Tres de las afirmaciones más destacadas hasta el momento: (1) que las obras literarias son transhistóricas (esto es, que no quedan confinadas a ser solamente la expresión de una situación histórica objetiva); (2) que la producción literaria goza de una esencia marcadamente material; y (3) que el objeto sobre el que opera la literatura es el conjunto diversificado de discursos y de representaciones que constituyen espontáneamente, el «lenguaje de la vida social» - por tomar una fórmula de Marx (1974: 25) - dimanan directamente de las consideraciones realizadas por Althusser a propósito de la ideología. Para Althusser, efectivamente, la ideología representa, en su deformación necesariamente imaginaria, no las existentes relaciones de producción (y las otras relaciones que de ellas se derivan), sino, sobre todo, la relación imaginaria de los individuos con sus condiciones reales de existencia (Althusser, 2014: 125). Su definición tiene, pues, un sentido positivo que la distancia de la descripción puramente negativa aportada en La ideología alemana (1845-1846) y continuada por Lu- 
kács -y por la Ideologiekritik de Adorno $^{22}$-: ahora la ideología puede ser productiva y no solo una deformadora "cámara oscura» (Marx, 1974: 26); su condición «imaginaria» la convierte en una estructura representacional apta para la confección de fantasías o relatos cotidianos que, interpelando a los individuos, justifiquen o den sentido a las relaciones vividas por ellos en el seno de la estructura social establecida. De ella dice Althusser que "no tiene historia»-o, en otras palabras, que es omnihistórica, en el sentido de que, más allá de sus encarnaciones particulares (ideologías religiosas, morales, jurídicas, políticas, etc.), su estructura y su funcionamiento están presentes en la historia entera tal como la define clásicamente el materialismo histórico (la historia de las sociedades de clases) - y se la sitúa en relación directa con la proposición de Freud de que el inconsciente es eterno, entendiendo este atributo como «lo omnipresente, lo transhistórico y por tanto inmutable en toda la extensión de la historia» (Althusser, 2014: 122-123).

A esta primera disensión respecto a la temprana idea lukácsiana de la falsa conciencia, se le suma otra precisión de igual importancia: la ideología tiene una existencia material (perceptible en las prácticas de los aparatos ideológicos de Estado ${ }^{23}$ ). Como ya hemos sugerido en el apartado anterior, Macherey integra las enseñanzas althusserianas al concebir la literatura como una forma ideológica cuya carga es mayoritariamente inconsciente y contradictoria ${ }^{24}$. Y no porque exprese, como los sueños según Freud, las ambiciones soterradas de esa parte del psiquismo de su autor, sino

\footnotetext{
${ }^{22}$ Tampoco en Adorno se percibe, en la crítica de la ideología contenida en su obra, un concepto positivo de ideología. Se trata para él, como es ya tradicional, de un lugar ficticio donde se reconcilian los intereses sociales antagónicos. En su traducción del conflicto político a términos espirituales, la deformación que produce la ideología es doble: subjetiva como «falsa conciencia» y objetiva por cuanto remite al fetichismo de la mercancía sistémico y constitutivo del modo de producción capitalista. En resumen: «las ideologías propiamente dichas sólo se convierten en falsas a través de su relación con la sociedad existente. Pueden ser verdaderas en sí tal como lo son las ideas de libertad, humanidad, justicia, pero se comportan como si se hubieran realizado ya» (Adorno, 2004: 442).

${ }^{23}$ A la clásica teoría marxista del Estado que lo concebía esencialmente como un aparato represivo, Althusser -prolongando las reflexiones de Antonio Gramsci en los Cuadernos de la cárcel (1929-1935) sobre la sociedad civil- agrega la presencia de otras instancias, los aparatos ideológicos de Estado (AIE), pertenecientes la mayoría al ámbito privado. Algunos ejemplos serían: el AIE religioso (el sistema de iglesias), el AIE escolar (las escuelas públicas y privadas), el AIE político (el sistema de partidos), el AIE de información (los medios de comunicación) o el AIE cultural (literatura, arte, deportes, etc.), entre otros. Véase Althusser (2014: 120 y ss.).

${ }^{24}$ También para Althusser (1977: 239-240) la ideología es en sí misma "profondément inconsciente [...], est bien un système de représentations: mais ces représentations n'ont la plupart du temps rien à voir avec la "conscience»: elles sont la plupart du temps des images, parfois des concepts, mais c'est avant tout comme structures qu'elles s'imposent à l'immense majorité des hommes, sans passer par leur "conscience"”.
} 
por cuanto, precisamente, problematiza -en ningún caso solamente reproduce- de modos no siempre conocidos o anticipados por el autor esa sustancia amorfa de la vida cotidiana que es la ideología (Macherey, 2014: 91), un poco a la manera en la que opera el «inconsciente político» de Jameson ${ }^{25}$. Lo hace a través de prácticas históricamente constatables, de naturaleza lingüística en gran medida: por ejemplo, es la época burguesa la que, mediante un proceso general de escolarización, establece una lengua nacional común con la que producir los efectos de ficción necesarios para la reproducción de la ideología burguesa como ideología dominante ${ }^{26}$. Es el aparato ideológico escolar, destinado a reproducir la división social del trabajo, el que genera una división lingüística entre la lengua elemental y la lengua literaria (Macherey y Balibar, 1974: 34-35) ${ }^{27}$. Comoquiera que sea, las prácticas lingüísticas no son utilizables como una mera materia prima: toda utilización es ya una intervención, lo cual implica que la simple réplica ideológica queda en sí misma excluida. De acuerdo con ello, la objetividad de la literatura radica en su intervención necesaria en el proceso de determinación y de reproducción de las prácticas lingüísticas contradictorias de una lengua común, donde se realiza la eficacia ideológica de la escolarización burguesa.

Macherey rechaza la falsa dialéctica de la forma y el contenido en la que muchas de las discusiones marxistas se hallan atrapadas. Reconocer en la literatura una forma ideológica determinada no significa reducir la literatura a las ideologías morales, políticas, religiosas e incluso estéticas que son definibles fuera de ella; tampoco significa hacer de esas ideologías el contenido al que la literatura vendría a aportar

${ }^{25}$ En The political unconscious. Narrative as a socially symbolic act (1981), Jameson sienta las bases de su método interpretativo de cariz alegórico, el metacomentario, que integra algunos de los hallazgos postestructuralistas más sonados y a partir del cual se puede emprender «el desenmascaramiento de los artefactos culturales como actos socialmente simbólicos (Jameson, 1989: 18). El reconocimiento hermenéutico del inconsciente político quiere decir que no existe documento que no sea extracto de la vida cotidiana y de la experiencia fantaseadora individual y, paralelamente, de carácter profundamente social e histórico.

${ }^{26}$ En el contexto del Estado español, el profesor Juan Carlos Rodríguez, quien fuera también discípulo de Althusser y recibiera las influencias de Macherey, consideraba que la Literatura, en tanto que expresión y producción de la idea del sujeto libre, "no ha existido siempre»; se trataría, más bien, de un fenómeno inequívocamente burgués surgido entre los siglos XIV y XVI que opera en lo simbólico gracias a la acción del «inconsciente ideológico»: "La literatura es la elaboración del trauma o de las pulsiones psíquicas a través de la configuración ideológica; la manera de decir “yo”, “уo soy”» (Rodríguez, 2016: 166-167).

${ }^{27}$ Una tesis similar sostiene Pierre Bourdieu en Ce que parler veut dire. L'économie des échanges linguistiques (1982), donde repasa los efectos de la legitimación e imposición de una lengua oficial en el contexto del sistema escolar francés, cuyo resultado es la distribución desigual del capital lingüístico y el refuerzo de la «dominación simbólica» (Bourdieu, 1982: 33 y ss.), y su impacto en la constitución del mercado literario. 
una forma especial. El problema en realidad es otro: el de la especificidad de los efectos ideológicos producidos por la literatura y el modo o mecanismo en que esta los produce (Macherey y Balibar, 1974: 37). Entonces, el análisis materialista de la literatura, habiendo recusado desde el principio la noción de «obra» -es decir, la representación ilusoria de la unidad del texto como una totalidad completa perfecta en su género y que se basta a sí misma-, no ha de buscar en los textos los signos de su propia cohesión, sino los indicios de las contradicciones históricas que los producen, los cuales se encuentran en ellos bajo la forma de conflictos irresueltos. Lo que produce el texto literario son una o varias contradicciones ideológicas que no pueden ser resueltas como tales en la ideología. Ello quiere decir que la literatura propone una solución imaginaria de esas contradicciones ideológicas irreconciliables realmente existentes «dans la mesure où elles sont formulées dans un langage spécial, à la fois différent de la langue commune et intérieur à celle-ci [...], réalisant et masquant, dans une série de formations de compromis, le conflit qui la constitue» (Macherey y Balibar, 1974: 39). En otras palabras: la literatura realiza por adelantado la ficción de su conciliación posible. Pero, si la obra literaria subraya las contradicciones que se producen en el seno de una ideología o da forma a aquello que, atendiendo a la definición althusseriana, es informe (la ideología), es precisamente porque, más que ser la expresión de una ideología (su «mise en mots»), el texto literario es ante todo su exhibición (su «mise en scène»). Así pues, son los procedimientos formales propios de la literatura (el uso de la ficción, los temas, los motivos, las figuras, etc.) y sus estrategias y operaciones de combinación -o sea, el hecho mismo de que la literatura sea eminentemente un «affaire de forme»- los elementos que posibilitan una transformación efectiva de la ideología sin llegar a ser jamás el reflejo exacto de una realidad material.

\section{Conclusiones}

A lo largo de las páginas precedentes hemos constatado la superación del modelo normativo de Lukács que basaba la aceptabilidad del canon estético en el grado de fidelidad temático-formal de las obras con respecto a la realidad, lo cual encumbraba forzosamente al realismo del XIX y denostaba las creaciones vanguardistas voluntariamente subjetivistas y distorsionadoras. Juzgado demasiado rígido y excesivamente clasicista, este modelo es criticado abiertamente por Goldmann y por Macherey, principalmente en lo que concierne a su condena moral al arte de vanguardia: ninguno comparte la idea de que la literatura de vanguardia sea decadente y connote deformación, declive o debilitamiento. Nombres como los de Proust, Woolf, Kafka, o Beckett $-\mathrm{y}$, como el debate adquiere casi por obligación coordenadas nacionales, también los de Sarraute o Robbe-Grillet- son repetidamente alabados. Goldmann, un lukácsiano explícitamente acérrimo por cuanto asume la validez de la noción de totalidad, considera asimismo que, más que desfigurarla, el modernismo deviene la expresión artística de la realidad histórica contemporánea. 
En este sentido, la estética adorniana, cuya permanente apología del modernismo nace de la consideración de que este ofrece un retrato preciso de la experiencia alienante y totalizadora de la vida social en el capitalismo tardío, es la que mejor parece encarnar a este respecto la voluntad de los teóricos franceses. Goldmann es quizás quien desarrolla con más cuidado los puntos de contacto con Adorno cuando propone que la narrativa modernista de la ausencia plasma los valores negativos asociados a la deshumanización de la vida social. Se observa, entonces, que la preocupación por articular una visión histórica no disminuye -al fin y al cabo ambos se consideran marxistas, y el marxismo puede calificarse como un tipo de historicismo materialista y dialéctico-, sino que cambia de orientación: si para Lukács la tipicidad propia del realismo clásico garantizaba la verdadera comprensión de los entresijos de la sociedad burguesa, lo que sucede ahora es que el modernismo es el nuevo escaparate de lo típico, y por tanto, en dichas circunstancias, su utilidad para transformar la sociedad es la misma. Comoquiera que sea, el acuerdo existente en relación a la aceptación definitiva del modernismo es evidente y conlleva la proclamación sin ambages de la libertad formal de los escritores. En última instancia, la causa responsable de ello es el rechazo del carácter cognoscitivo de la literatura -o, lo que es lo mismo, el repudio de la teoría del reflejo, que implica la conversión de una categoría gnoseológica en una noción estética-, común a la mayoría y especialmente intenso en Macherey. El arte no puede ser una forma de conocimiento porque, como había dicho Adorno, el contenido de verdad expresado en las obras de arte no es de naturaleza documental, sino estética (es decir, subjetiva o ideológica).

Macherey opta por desarrollar las ideas seminales de Benjamin y de Brecht a propósito del autor como productor. Más que ofrecer una respuesta definitiva a la pregunta sobre cuál es el rol productivo del autor literario y cómo se materializa este en el consumo de las obras que hace el público lector, Macherey intenta esbozar cómo la literatura exhibe y problematiza, no siempre conscientemente, las contradicciones ideológicas de los sistemas de pensamiento hegemónicos. Parece evidente que la manera específica con que la literatura refleja la realidad no es objetiva desde el punto de vista figurativo, pues los procedimientos formales constitutivos de la literariedad incluyen mecanismos de deformación o desfiguración (lo fantástico, la parábola, el símbolo...) que no obstante favorecen, como sostenían Brecht y aún antes Sklovski, la captación de las incoherencias de la ideología dominante. A la vez, Macherey constata que las obras literarias están dotadas de cierta autonomía relativa que impide su reducción a mero fenómeno ideológico, aunque ello tampoco es óbice para que rechace la famosa finalidad sin fin del arte enunciada por Kant, o, en otras palabras, la doctrina de l'art pour l'art. En definitiva, las repetidas alusiones de Macherey a personalidades que de una forma $\mathrm{u}$ otra intervinieron o comentaron muchas de las cuestiones que hemos analizado aquí -como Genette, Barthes, Jauss, Bourdieu o Zima, entre otros-, o el impacto que la noción de producción literaria tuvo en teóricos 
marxistas de la literatura posteriores -como Terry Eagleton, que ha teorizado sobre el «modo literario de producción» (MLP), Fredric Jameson, que en 2013 publicó The Antinomies of Realism, un extenso trabajo sobre las contradicciones surgidas en la relación entre el realismo y la modernidad capitalista o, en España, Juan Carlos Rodríguez-, demuestran en efecto que su propuesta teórica, al proponer colateralmente un discurso general sobre la literatura y el arte, ha suscitado un interés exógeno que a su vez marcó con su impronta en grados variables al resto de escuelas.

\section{REFERENCIAS BIBLIOGRÁFICAS}

Adorno, Theodor W. (2004): Dialéctica negativa. Obra completa, 6. Traducción de Alfredo Brotons Muñoz. Madrid, Akal.

ALTHUSSER, Louis (1968): «Sobre el conocimiento del arte (respuesta a André Daspre)». Ideas y Valores, 30-31, 7-11.

ALTHUSSER, Louis (2014): La filosofía como arma de la revolución. Traducción de Óscar del Barco, Enrique Román y Óscar L. Molina. Barcelona, Anthropos.

Althusser, Louis (1974): Para una crítica de la práctica teórica. Respuesta a John Lewis. Traducción de Santiago Funes. Madrid, Siglo XXI.

Althusser, Louis (1977): Pour Marx. París, François Maspero.

ARAGON, Louis; Fernand LEGER et al. (1987): La Querelle du réalisme. París, Éditions Cercle d'Art.

BALIBAR, Étienne (2007): «El estructuralismo: ¿una destitución del sujeto?» Instantes y Azares: Escrituras Nietzscheanas, 4-5, 155-172.

BARTHES, Roland; Henri LEFEBVRE; Lucien GOLDMANN et al. (1969): Literatura y sociedad. Problemas de metodología en sociología de la literatura. Traducción de R. de la Iglesia. Barcelona, Ediciones Martínez Roca.

BARTHES, Roland (2002): Ensayos críticos. Traducción de Carlos Pujol. Barcelona, Seix Barral.

BARTHES, Roland (1970): S/Z. París, Éditions du Seuil.

Benjamin, Walter (1990): El origen del drama barroco alemán. Traducción de José Muñoz Millares. Madrid, Taurus.

Benjamin, Walter (2012): Escritos políticos. Traducción de Alfredo Brotons Muñoz y Jorge Navarro Pérez. Madrid, Abada.

BOURDIEU, Pierre (1985): ¿Qué significa hablar? Economía de los intercambios lingüisticos. Traducción de Esperanza Martínez Pérez. Madrid, Akal. 
BRECHT, Bertolt (2004): Escritos sobre teatro. Traducción de Genoveva Dieterich. Barcelona, Alba Editorial.

COnTAT, Michel y Michel RYBalKa (1970): Les Écrits de Sartre. París, Gallimard.

DelaVEAU, Anne y Françoise Kerleroux (1970). «Pour qui écrivez-vous ? À propos de Pour une théorie de la production littéraire» de Pierre Macherey». Langue française, 7, 76-86.

DURKHEIM, Émile (1967): De la division du travail social. París, PUF.

FABRE, Gérard (2001): Pour une sociologie du procès littéraire, de Goldmann à Barthes en passant par Bakhtine. París, L'Harmattan.

FISCHER, Ernst (1970): À la recherche de la réalité. Contribution à une esthétique marxiste moderne. Traducción de Jean-Louis Lebrave y Jean-Pierre Lebrave. París, Denoël.

FOUCAUlT, Michel (1969): «Qu'est-ce qu'un auteur ?». Bulletin de la Société française de philosophie, 63/3, 73-104.

GIRARD, René (1985): Mentira romántica y verdad novelesca. Traducción de Joaquín Jordá. Barcelona, Anagrama.

GoldmanN, Lucien (1948): La Communauté humaine et l'univers chez Kant : études sur la pensée dialectique et son histoire. París, Presses universitaires de France.

GoldmanN, Lucien (1959): Le Dieu caché. París, Gallimard.

GoldmanN, Lucien (1964): Pour une sociologie du roman. París, Gallimard.

GoldmanN, Lucien (1966): Sciences humaines et philosophie. París, Éditions Delga.

Goldmann, Lucien (1970): Structures mentales et création culturelle. París, Anthropos.

Goldmann, Lucien (1977): Structuralisme génétique. París, Denoël/Gonthier.

GOLDMANN, Lucien y Theodor W. ADORNO (1972): «Deuxième colloque international sur la Sociologie de la Littérature». Revue de l'Institut de Sociologie, 3-4, 523-540.

Hegel, G. W. F. (1991): Phénoménologie de l'Esprit. Traducción de Jean-Pierre Lefebvre. París, Aubier.

JAMESON, Fredric (1989): Documentos de cultura, documentos de barbarie. Traducción de Tomás Segovia. Madrid, Visor.

JAUSS, Hans Robert (2013): La historia de la literatura como provocación. Traducción de J. Godo Costa y J. L. Gil Aristu. Madrid, Gredos.

Lefebvre, Henri (2001): Contribution à l'esthétique. París, Anthropos.

LuKACS, György (1968): Sociología de la literatura. Traducción de Michael FaberKaiser. Barcelona, Península. 
LUKÁCS, György (2010): Teoría de la novela. Traducción de Micaela Ortelli. Buenos Aires, Ediciones Godot.

MACHEREY, Pierre (2009): «La cosa literaria» Nómadas, 31, 113-123.

MACHEREY, Pierre (2013): Philosopher avec la littérature. París, Hermann Éditeurs.

Macherey, Pierre (2014): Études de philosophie littéraire. París, De l'Incidence Éditeur.

MACHEREY, Pierre (2014): Pour une théorie de la production littéraire. Lyon, ENS Éditions.

MACHEREY, Pierre y Étienne BALIBAR (1974): «Sur la littérature comme forme idéologique. Quelques hypothèses marxistes». Littérature, 13, 29-48.

MARTín Morales, José-Alberto (1971): «Ideas estéticas de Lucien Goldmann en su entronque con las de Lukács». Arbor, 78(302), 173-186.

MARX, Karl (1974): La ideología alemana. Traducción de Wenceslao Roces. Barcelona, Grijalbo.

MARX, Karl (1982): Introducción general a la crítica de la Economía Politica. Traducción de José Aricó y Jorge Tula. México D. F., Siglo XXI.

MAYORGA, René Antonio (1982): «Ideología y crítica de la ideología: reflexiones en torno a una alternativa teórica», in Daniel Camacho; José Luis Najenson; René Antonio Mayorga et al., América Latina: ideología y cultura. San José, Ediciones FLACSO, 115-156.

NoguerA, José Antonio (2011): «El concepto de trabajo y la teoría social crítica». Travailler, 26/2, 161-192.

Perottino, Serge (1974): Roger Garaudy et le marxisme du XXe siècle. París, Seghers.

RodrígueZ, Juan Carlos (2016): Pensar la literatura. Entrevistas y bibliografía (19612016). Granada, Asociación ICILe Los libros imposibles.

SASSO, Javier (1979): Sobre la sociología de la creación literaria. Examen de las tesis de Goldmann. Xalapa, Universidad Veracruzana.

ZIMA, Pierre V. (1999): «Idéologie, théorie et altérité : l'enjeu éthique de la critique littéraire». Études littéraires, 31/3, 17-30.

ZIMA, Pierre V. (2000): Pour une sociologie du texte littéraire. París, L'Harmattan. 